\title{
Comparison of clinical practice guidelines for the management of pregnant women with COVID-19 infection: a review
}

\author{
Diane Nzelu ${ }^{1}$, Angela $\operatorname{Sin}^{1}$, and Aisha Hameed ${ }^{1}$ \\ ${ }^{1}$ KINGS COLLEGE HOSPITAL NHS TRUST
}

May 27, 2020

\begin{abstract}
Coronavirus Disease 19 (COVID-19) is caused by severe acute respiratory coronavirus-2 and has resulted in an unprecedented global pandemic. The adaptations of pregnancy often predispose pregnant women to a more severe course of respiratory illness with the potential for maternal and perinatal morbidity. Thus, national and international guidelines are rapidly being developed to help maintain optimal care throughout pregnancy. Due to the novelty of COVID-19 and limitations of existing data, heterogeneity exists between these guidelines. We aim to review the available evidence for the management of pregnant women with COVID-19 and summarise the recommendations set out by three main institutions.
\end{abstract}

\section{TWEETABLE ABSTRACT}

Disagreement exists between national and international guidelines on management of pregnant women with COVID-19 infection.

\section{INTRODUCTION}

Coronavirus Disease 19 (COVID-19) is caused by severe acute respiratory coronavirus-2 (SARS-COV-2), which is a novel strain of coronavirus that first appeared in December 2019 in Hubei Province, China. ${ }^{1}$ Since then, the spread of SARS-COV-2 has resulted in an unprecedented global pandemic infecting over 4 million people and killing approximately 300,000 as of May 2020. ${ }^{2}$ SARS-COV-2 infection causes a spectrum of clinical manifestations from asymptomatic viral shedding or mild symptoms resembling those of the common cold to severe influenza-like illness and viral pneumonia. ${ }^{1}$ The global mortality rate reported by the World Health Organisation is approximately 3.4 percent. $^{2}$

The maternal adaptations to pregnancy can often predispose pregnant women to a more severe course of respiratory illness. ${ }^{3}$ Certainly, in two previous epidemics over the last 2 decades caused by similar coronaviruses, MERS and SARS, pregnant women experienced both a higher morbidity and mortality rate when compared to the non-pregnant population. ${ }^{4,5}$ The UK Obstetric Surveillance System recently published a national cohort study including 427 women with COVID-19 infection in pregnancy mostly in the second and third trimester. ${ }^{6}$ The commonest symptoms were pyrexia followed by cough and breathlessness. Approximately 1 in 10 pregnant women compared to 1 in 100 non-pregnant women required critical care admission. ${ }^{6}$ However, there is insufficient evidence at present to conclude from this data that pregnant women are more susceptible to COVID-19 or that those with COVID-19 infection are more prone to developing severe pneumonia.

The unique requirements of pregnancy with the potential for perinatal and maternal morbidity present a significant challenge to our maternity services. This demands a unified response from national and international organisations to ensure an evidence-based and coherent approach in the management of pregnant women with COVID-19. Thus, guidelines are rapidly being developed in the UK by the Royal College 
of Obstetricians and Gynaecologists (RCOG) ${ }^{7}$ and, internationally, by the International Federation of Obstetrics \& Gynaecology (FIGO) ${ }^{8}$ and the International Society of Ultrasound in Obstetrics \& Gynaecology (ISUOG).${ }^{9}$ However, due to the novelty of the infection, the evidence currently available to guide clinical management is limited consisting mainly of observational studies and systematic reviews that quickly go out of date.

Our objectives are, first, to compare the recommendations set out in the most recent version of the RCOG guidelines on the management of COVID-19 infection in pregnancy with those in the international guidelines published by ISUOG and FIGO and, second, to review the supporting evidence for these recommendations.

\section{ANTENATAL MANAGEMENT OF WOMEN WITH COVID-19 INFECTION}

Based on currently available data, the clinical characteristics of pregnant women with COVID-19 infection are similar to those of non-pregnant adults. This includes the risk of progression to severe respiratory disease and need for mechanical ventilation with reported rates of between 1.6 to 5.3 percent, similar to that of the non-pregnant population. ${ }^{10,11}$

COVID-19 infection does not appear to increase the risk of adverse pregnancy outcomes. The only casecontrol study available that compares pregnant women with COVID-19 infection to those without did not demonstrate any differences in the rates of preeclampsia, gestational diabetes and premature rupture of membranes. ${ }^{12}$ These findings were in agreement with a systematic review of 114 pregnant women with COVID-19 infection, which concluded that the maternal and perinatal outcomes appeared similar to the general obstetric population. ${ }^{10}$ In contrast, another systematic review evaluating pregnancy outcomes in 79 women with COVID-19 infection suggested higher rates of preterm birth before 37 and 34 weeks (41.1 and 15 percent, respectively), premature rupture of membranes (18.8 percent) and preeclampsia (13.6 percent). ${ }^{13}$ Similarly, 17 percent of those with COVID-19 infection in pregnancy included in the UKOSS study delivered before 37 weeks compared to only 8 percent in those without. ${ }^{6}$ Although the association between COVID-19 infection in pregnancy and adverse outcomes remains to be determined, there is a well-established relationship between other viral pneumonias and pre-term birth and/or premature rupture of membranes. ${ }^{3,14}$ Therefore, It is possible that as the pandemic evolves and the quality of evidence improves, a similar association with COVID-19 may emerge. Furthermore, it remains unknown as to the impact of COVID-19 infection when occurring early in pregnancy due to the lack of first trimester data.

Higher rates of fetal growth restriction (FGR) have not so far been reported with COVID-19. However, in one case series and one systematic review that evaluated outcomes of pregnancies complicated by SARS, a significantly higher incidence of FGR was demonstrated with rates of 16.6 and 18.5 percent, respectively. ${ }^{4}, 13$ Based on this data and until more evidence is available for COVID-19, ISUOG recommend 2 to 4 weekly fetal ultrasound assessment ${ }^{9}$ and $\mathrm{FIGO}^{8}$ recommend monthly. The RCOG does not make any recommendation as to the frequency of ultrasound assessment in women with COVID-19 infection in pregnancy but states that, during the pandemic, non-routine growth scans that are not guidance-based should be kept to a minimum. ${ }^{7}$

Outside of pregnancy, women of black racial origin have a 4-fold increase in the risk of death from COVID19 when compared to their white counterparts. ${ }^{15}$ A number of theories have been proposed to account for this trend. These include genetic, health and socioeconomic disparities leading to increased exposure and susceptibility to COVID-19 infection in those of black racial origin such as a higher prevalence of hypertension and diabetes ${ }^{16}$ or ethnic variations in the expression of angiotensin converting enzyme 2 , the host receptor of SARS-CoV-2. ${ }^{17}$ Similarly, in pregnancy, COVID-19 appears to have a more severe impact on those of black and ethnic minority with an almost 4-fold increase (OR 3.67, 95\% CI 2.55-5.28) in the risk of needing hospital admission even after adjustment for body mass index, co-morbidities, age and geographical location. ${ }^{6}$ Prior to the pandemic, pregnant women of black racial origin were already disproportionately represented amongst those who died with a 5 -fold increase in the risk of death. ${ }^{18}$ In recognition of this, the RCOG guidelines recommend that pregnant women of black and ethnic minority background and clinicians should have a much lower threshold to escalate care should there be concerns regarding their health. ${ }^{7}$

To minimise the risk of transmission to other pregnant women and healthcare providers, any scheduled 
antenatal appointments in women with COVID-19 infection should be delayed until after the period of selfisolation. If obstetric or midwifery appointments are deemed necessary and cannot be carried out virtually, then all guidelines recommend that those appointments are kept to the end of the day and that staff are notified of the need to wear Personal Protection Equipment (PPE) with subsequent deep cleaning of the room and any equipment utilised..$^{7-9}$ There is no evidence for the above recommendations regarding antenatal appointments but are largely based on expert opinion.

\section{INTRA-PARTUM CARE OF WOMEN WITH COVID-19 INFECTION}

COVID-19 itself is not an indication for delivery. ${ }^{19}$ However, the advice for the timing of delivery and the intra-partum care of women with COVID-19 infection should be determined by their clinical status. ${ }^{19}$ RCOG recommend that if the symptoms are mild then standard practice guidelines prevail regarding the management of the latent phase of labour at home. ${ }^{7}$

In the existing literature, the caesarean section rate in pregnant women with COVID-19 infection is between 69.4 and 91 percent. ${ }^{10,11,13,20}$ The indications, where reported, are mostly due to maternal condition, premature rupture of membranes, preeclampsia, fetal distress or unknown risk of intra-partum vertical transmission with vaginal delivery. ${ }^{10,13,20}$ Despite this, all guidelines agree that vaginal delivery is not contraindicated in women with COVID-19 infection and that caesarean section should only be performed for the usual indications. ${ }^{7-9}$ ISUOG and FIGO state that there should be a lower threshold for expediting delivery because of the risk of fetal distress and deterioration in maternal condition. ${ }^{8,9}$

Continuous fetal monitoring is recommended by all clinical guidelines. Evidence from case series and two systematic reviews suggest a rate of up to 43 percent of intrauterine fetal distress occurring during the active labour in women with COVID-19 infection. ${ }^{10,12,13}$ The place of birth is recommended to be a negative pressure isolation room as per FIGO and ISUOG guidelines or, in the absence of a negative pressure ventilation system, an isolation room as per RCOG guidelines. ${ }^{7-9}$

For healthcare professionals caring for all women with COVID-19 infection in the second or third stage of labour, ISUOG and FIGO advise on the use of a fit-tested N95 mask, FFP2 or equivalent standard respirator, eye protection, disposable fluid resistant gown and double gloves. ${ }^{8}{ }^{9}$ The RCOG recommend the use of a fluid resistant surgical mask, eye protection, disposal fluid resistant gown and single gloves with the respirator masks being reserved for aerosol generating procedures. ${ }^{7}$ Respirator masks such as the N95 are designed to fit tightly to the wearers face and prevent the inhalation of small-aerosolised particles. ${ }^{21}$ On the other hand, surgical masks fit loosely to the wearers face and prevent facial contact with large droplets but do not reliably prevent inhalation of small-aerosolised particles. ${ }^{21}$ Respiratory viruses such as SARS-COV-2 are primarily transmitted through hand to face contact with large respiratory droplets. ${ }^{1}$ Studies have not demonstrated any difference between surgical and N95 masks in the prevention of droplet transmission of other similar respiratory viruses such as influenza. ${ }^{21}$ In the absence of evidence to suggest that the second stage of labour generates aerosolised particles, the RCOG consider the surgical mask to be adequate for droplet/contact precaution and, thus, offer sufficient protection for healthcare professionals offering intra-partum care to those with COVID-19 infection. ${ }^{7}$

The use of antenatal steroids for fetal lung maturation has also been debated. The routine use of systemic steroids in the setting of viral pneumonia has previously been associated with increased maternal morbidity. ${ }^{22}$ One study has demonstrated delayed virus clearance with the administration of steroids and MERS. ${ }^{23}$ Finally and specifically with COVID-19, there is a relationship between steroid use and increased mortality $(\mathrm{RR}=2.11,95 \% \mathrm{CI}=1.13-3.94, \mathrm{P}=0.0190) .{ }^{24}$ However, in general, these studies do not control for baseline morbidity and the course of steroids was longer than the 2-day course given for fetal lung maturity. Currently, the RCOG recommend that antenatal steroids should be given even in the context of COVID-19 when indicated such as in the event of preterm labour. ${ }^{7}$ In contrast, the ISUOG and FIGO guidelines urge caution in the use of antenatal steroids in women with COVID-19 infection and recommend close liaison with a specialist in maternal-fetal medicine. ${ }^{8,9}$ This is because the absolute benefit of antenatal steroids reduces with advancing gestational age, is partly influenced on the presence of FGR and warrants careful evaluation 
of the maternal condition prior to them being given. ${ }^{25}$

All guidelines unanimously agree on the safety of regional anaesthesia for the purpose of analgesia in labour in women with COVID-19. RCOG advise that the use of epidural in labour is recommended for women with COVID-19 to minimise the need for general anaesthetic, an aerosol generating procedure, should emergency delivery be indicated. ${ }^{7-9}$ Shortening of the second stage may be required with the use of an instrumental delivery as per ISUOG, FIGO and RCOG guidelines due to the mother's respiratory status and potential for exhaustion. ${ }^{7-9}$

\section{POST DELIVERY/NEONATAL MANAGEMENT OF WOMEN WITH COVID-19 INFEC- TION}

Delayed clamping of the umbilical cord remains a controversial issue. ISUOG and FIGO guidelines both recommend prompt clamping of the cord and transfer of the neonate to the resuscitation area for evaluation by the paediatric team. ${ }^{8}{ }^{9}$ In contrast and in recognition of the lack of evidence to suggest otherwise, the RCOG continue to recommend delayed cord clamping. ${ }^{7}$ According to WHO, delayed cord clamping is highly unlikely to increase the risk of vertical transmission of pathogens even in the context of maternal infection. ${ }^{26}$ Furthermore, to date, no positive RT-PCR results have been found in the amniotic fluid, placenta or cord blood of the studied population. In the UKOSS cohort, 6 infants born to 244 women hospitalised with COVID-19 infection tested positive for SARS-COV-2 RNA, with only one infant requiring admission to the neonatal intensive care unit. Another systematic review including 256 infants born to women with COVID19 infection reported only 4 who were RT-PCR positive for SARS-COV-2 RNA within the first 36 hours of birth. ${ }^{11}$ Again, samples from their cord blood, placenta and amniotic fluid were all negative and all 4 infants had an uncomplicated recovery. Therefore, there is no conclusive evidence at present of fetal infection via intrauterine vertical transmission. Considering the well-known clinical benefits to the neonate of delayed cord clamping, there is some concern amongst experts that recommending otherwise in women with COVID-19 in the absence of sufficient evidence could be harmful.

There is currently limited evidence regarding the safety of breastfeeding and the need for mother-baby separation. In view of this, all guidelines advise against universal isolation of neonates born to mothers with COVID-19 infection and that it may only be appropriate if the mother is critically ill. An alternative to separation suggested by FIGO and ISUOG guidelines is 'co-rooming' where the baby's cot is kept at least 2 metres from the mothers bed. ${ }^{8}, 9$ The main concern of breastfeeding is the risk of transmitting SARS-COV-2 from the mother to the baby via respiratory droplets rather than the breast milk itself. All samples of breast milk have so far tested negative for SARS-COV-2. ${ }^{11}$ The RCOG, ISUOG and FIGO guidelines all advise that those who wish to breast feed, should the maternal condition allow, continue to do so. However, precautions should be taken such as hand washing and the use of a surgical mask by the mother to prevent viral spread to the baby. ${ }^{7-9}$

The highest risk of venous thromboembolism (VTE) is during the first six weeks of the postnatal period with a 12 -fold increase compared to the non-pregnant, non-postpartum population. ${ }^{27}$ Furthermore, emerging evidence shows that COVID-19 is associated with significant coagulopathy namely disseminated intravascular coagulation leading to VTE. ${ }^{28}$ Although the risk remains highest in those who are critically unwell, representing only about 5 percent of the population with COVID-19, the impact on VTE risk in those with mild to moderate disease remains unknown. ${ }^{28}$ Thus, the RCOG recommend that, following birth, all women with COVID-19 infection should be discharged with at least 10 days of treatment with low molecular weight heparin or longer should additional risk factors be present. ${ }^{7}$

\section{CONCLUSION}

In conclusion, heterogeneity exists amongst the current guidance published by national and international bodies in the management of COVID-19 infection in pregnancy. This is likely a reflection of limitations in the existing evidence due to the novelty of the disease or variations in healthcare settings and resources available. However, effort should be taken to coordinate the response to COVID-19 in our pregnant population to ensure optimal provision of care during this pandemic and allow for better extrapolation of data in the long-term. 


\section{DISCLOSURE OF INTERESTS}

The authors declare no conflict of interest

\section{CONTRIBUTION TO AUTHORSHIP}

$\mathrm{DN}$ and AS were involved in the review of literature and drafted the manuscript. AH contributed to the conception and supervision throughout the study as well as the drafting and revision of the manuscript.

\section{ETHICS APPROVAL}

Ethics approval consideration was not required for this review article.

\section{FUNDING}

No funding was received.

\section{REFERENCES}

1. Huang C, Wang Y, Li X, Ren L, Zhao J, Hu Y, et al. Clinical features of patients infected with 2019 novel coronavirus in Wuhan, China.Lancet . 2020;395(10223):497-506.

2. World Health Organisation. Coronavirus disease (COVID-19); Situation Report - 114: World Heatlh Organisation 2020 [Available from: https://www.who.int/docs/default-source/coronaviruse/situationreports/20200513-covid-19-sitrep-114.pdf?sfvrsn=17ebbbe_4.

3. Chen YH, Keller J, Wang IT, Lin CC, Lin HC. Pneumonia and pregnancy outcomes: a nationwide population-based study. Am J Obstet Gynecol . 2012;207(4):288.e1-7.

4. Wong SF, Chow KM, Leung TN, Ng WF, Ng TK, Shek CC, et al. Pregnancy and perinatal outcomes of women with severe acute respiratory syndrome.Am J Obstet Gynecol . 2004;191(1):292-7.

5. Alfaraj SH, Al-Tawfiq JA, Memish ZA. Middle East Respiratory Syndrome Coronavirus (MERS-CoV) infection during pregnancy: Report of two cases \& review of the literature. J Microbiol Immunol Infect . 2019;52(3):501-3.

6. Knight M, Bunch K, Vousden N, Morris E, Simpson N, Gale C, et al. Characteristics and outcomes of pregnant women hospitalised with confirmed SARS-CoV-2 infection in the UK: a national cohort study using the UK Obstetric Surveillance System (UKOSS) 2020 [Available from: https://www.npeu.ox.ac.uk/downloads/files/ukoss/annual-reports/UKOSS COVID-19 Paper pre-print draft 11-05-20.pdf.

7. RCOG. Coronavirus (COVID-19) Infection in Pregnancy (Version 9). London: RCOG; 2020.

8. Poon LC, Yang H, Kapur A, Melamed N, Dao B, Divakar H, et al. Global interim guidance on coronavirus disease 2019 (COVID-19) during pregnancy and puerperium from FIGO and allied partners: Information for healthcare professionals. Int J Gynaecol Obstet . 2020;149(3):273-86.

9. Poon LC, Yang H, Dumont S, Lee JCS, Copel JA, Danneels L, et al. ISUOG Interim Guidance on coronavirus disease 2019 (COVID-19) during pregnancy and puerperium: information for healthcare professionals - an update. Ultrasound Obstet Gynecol . 2020;Online ahead of print.

10. Yang Z, Wang M, Zhu Z, Liu Y. Coronavirus disease 2019 (COVID-19) and pregnancy: a systematic review. J Matern Fetal Neonatal Med . 2020;Online ahead of print.

11. Elshafeey F, Magdi R, Hindi N, Elshebiny M, Farrag N, Mahdy S, et al. A systematic scoping review of COVID-19 during pregnancy and childbirth. Int J Gynaecol Obstet . 2020;Online ahead of print.

12. Li N, Han L, Peng M, Lv Y, Ouyang Y, Liu K, et al. Maternal and neonatal outcomes of pregnant women with COVID-19 pneumonia: a case-control study. Clin Infect Dis . 2020;Online ahead of print. 
13. Di Mascio D, Khalil A, Saccone G, Rizzo G, Buca D, Liberati M, et al. Outcome of Coronavirus spectrum infections (SARS, MERS, COVID 1 -19) during pregnancy: a systematic review and meta-analysis. Am $J$ Obstet Gynecol MFM . 2020; Online ahead of print.

14. Getahun D, Ananth CV, Oyelese Y, Peltier MR, Smulian JC, Vintzileos AM. Acute and chronic respiratory diseases in pregnancy: associations with spontaneous premature rupture of membranes. J Matern Fetal Neonatal Med . 2007;20(9):669-75.

15. ONS. Coronavirus (COVID-19) related deaths by ethnic group, England and Wales: 2 March 2020 to 10 April 2020: Office for National Statistics 2020 [Available from: https://www.ons.gov.uk/peoplepopulationandcommunity/birthsdeathsandmarriages/deaths/articles/coronavirusrelateddeat

16. Tillin T, Forouhi NG, McKeigue PM, Chaturvedi N. Southall And Brent REvisited: Cohort profile of SABRE, a UK population-based comparison of cardiovascular disease and diabetes in people of European, Indian Asian and African Caribbean origins. Int J Epidemiol . 2012;41(1):33-42.

17. Bourgonje AR, Abdulle AE, Timens W, Hillebrands JL, Navis GJ, Gordijn SJ, et al. Angiotensinconverting enzyme-2 (ACE2), SARS-CoV-2 and pathophysiology of coronavirus disease 2019 (COVID-19). $J$ Pathol . 2020;Online ahead of print

18. Knight M, Bunch K, Tuffnell D, Shakespeare J, Kotnis R, Kenyon S, et al. Saving Lives, Improving Mothers' Care - Lessons learned to inform maternity care from the UK and Ireland Confidential Enquiries into Maternal Deaths and Morbidity 2015-17. National Perinatal Epidemiology Unit, University of Oxford: 2019 .

19. Chen D, Yang H, Cao Y, Cheng W, Duan T, Fan C, et al. Expert consensus for managing pregnant women and neonates born to mothers with suspected or confirmed novel coronavirus (COVID-19) infection. Int J Gynaecol Obstet . 2020;149(2):130-6.

20. Della Gatta AN, Rizzo R, Pilu G, Simonazzi G. Coronavirus disease 2019 during pregnancy: a systematic review of reported cases. Am J Obstet Gynecol . 2020;Online ahead of print.

21. Radonovich LJ, Jr., Simberkoff MS, Bessesen MT, Brown AC, Cummings DAT, Gaydos CA, et al. N95 Respirators vs Medical Masks for Preventing Influenza Among Health Care Personnel: A Randomized Clinical Trial.Jama . 2019;322(9):824-33.

22. Rodrigo C, Leonardi-Bee J, Nguyen-Van-Tam J, Lim WS. Corticosteroids as adjunctive therapy in the treatment of influenza. Cochrane Database Syst Rev . 2016;3:Cd010406.

23. Arabi YM, Mandourah Y, Al-Hameed F, Sindi AA, Almekhlafi GA, Hussein MA, et al. Corticosteroid Therapy for Critically Ill Patients with Middle East Respiratory Syndrome. Am J Respir Crit Care Med . 2018;197(6):757-67.

24. Yang Z, Liu J, Zhou Y, Zhao X, Zhao Q, Liu J. The effect of corticosteroid treatment on patients with coronavirus infection: a systematic review and meta-analysis. $J$ Infect . 2020;Online ahead of print.

25. Travers CP, Clark RH, Spitzer AR, Das A, Garite TJ, Carlo WA. Exposure to any antenatal corticosteroids and outcomes in preterm infants by gestational age: prospective cohort study. Bmj . 2017;356:j1039.

26. WHO. Guideline: Delayed umbilical cord clamping for improved maternal and infant health and nutrition outcomes. Geneva: World Health Organization; 2014.

27. Kamel H, Navi BB, Sriram N, Hovsepian DA, Devereux RB, Elkind MS. Risk of a thrombotic event after the 6-week postpartum period. N Engl J Med . 2014;370(14):1307-15.

28. Kollias A, Kyriakoulis KG, Dimakakos E, Poulakou G, Stergiou GS, Syrigos K. Thromboembolic risk and anticoagulant therapy in COVID-19 patients: emerging evidence and call for action. $\mathrm{Br} J$ Haematol . 2020; Online ahead of print. 